\title{
UpGrade do Macaco: grafite expandido
}

Fabrício Silveira

\section{Resumo}

0 grafite não é um objeto inusual no campo de estudos da Comunicação. Entretanto, há pelo menos uma certa naturalização do debate em torno do tema. Na imensa maioria dos trabalhos que, desde os anos 80, têm-se dedicado ao assunto, afirma-se o grafite entendendo seus aspectos comunicacionais muito diluídos na cultura urbana. 0 grafite seria assim uma forma de comunicação típica do ambiente da cidade. Em outros casos, menos numerosos, o grafite é muito rápida e genericamente equiparado a formas midiáticas mais instituídas (como o cartoon e 0 videoclipe, por exemplo). De qualquer modo, numa ou noutra perspectiva, não há a percepção de que um outro comunicacional, num sentido muito mais específico, pode estar sendo engendrado no histórico mesmo da grafitagem.

\section{Palavras-chave}

Grafite. Comunicação urbana. Remediação.

\section{Fabrício Silveira | fabricios@unisinos.br}

Doutor em Comunicação pela Universidade do Vale do Rio dos Sinos UNISINOS. Professor do Programa de Pós-Graduação em Comunicação da UNISINOS.

Trabalho apresentado no Núcleo de Pesquisa Comunicação e Culturas no XXXI Congresso Brasileiro de Ciências da Comunicação INTERCOM, 2008.

\section{Introdução}

Uma das discussões inevitáveis dentro do projeto de pesquisa "Novas figurações do grafite", que desenvolvemos desde março de 2007 junto ao PPGCCOM/UNISINOS, diz respeito justamente à legitimidade e à pertinência do tema - as tais "...figurações..." - no campo da Comunicação. Já de saída, em nosso percurso investigativo, uma série de questões se colocava: o grafite é (ou pode, ao menos, ser entendido como) um típico fenômeno comunicacional? Mais exatamente, o que é este específico comunicacional que supomos haver junto aos produtos da grafitagem? Ditas especificações (caso sejam mais de uma) são suficientemente dignas e satisfatórias - permitindo-nos assim operar com tranqüilidade em torno do grafite? Quais são, afinal de contas, os sentidos em que empregamos aqui o termo "comunicação" e que nos deixam aceitar, nesse campo de estudos, tal objeto de investigação?

Sobre essas interrogações de base a pesquisa deveria avançar. Antes de querer resolvê-las, contudo (e até mesmo para que pudéssemos 
tentar resolvê-las, sem pressa, no andamento dos trabalhos), pareceu-nos apropriado tomálas, inicialmente, como critério de recorte e composição do próprio corpus empírico adotado para 0 estudo. Em seguida, como desdobramento da mesma preocupação de fundo, pareceu-nos então sensato tomar aquele pacote de questões como chave e ângulo de leitura de parte da bibliografia que vem se acumulando, já há alguns anos, ao redor do tema, no interior e/ ou nas adjacências do campo da Comunicação. Assim estaríamos revendo e recolocando, na expectativa do melhor dimensionamento de nosso foco comunicacional, o material bibliográfico de que dispúnhamos sobre a cultura e as peças do grafite.

Impondo-se tais cautelas, o projeto não conseguiria desobrigar-se de encontrar (ou de tentar encontrar, que fosse...) o comunicacional mais estrito que pudesse $\mathrm{e}^{1}$. Basicamente, duas eram então as restrições aceitas para efeitos de defesa de pertinência e singularização de abordagem: uma, relativa à escolha dos objetos empíricos; outra, referente à definição do norte (ou modo) de leitura das fontes teóricobibliográficas disponíveis. Apostávamos que assim poderiam materializar-se - menos como formulação abstrata, mais como desenho concreto de operações - nossos necessários esforços de vigilância e cuidado epistêmicos.
Nesse quadro de limitações e regulagens autoimpostas, seria possível, por exemplo, entender o grafite não só como um objeto comunicacional, fracamente definido, mas como objeto e tema propriamente midiáticos - no sentido mais rigoroso que pudéssemos imaginar e atribuir ao termo? Poderíamos flagrar o grafite plenamente requalificado por lógicas midiáticas muito típicas, justificando-se então, desse modo, uma abordagem própria e particularizada, eqüidistante e francamente diferenciável - a despeito da natureza complexa do objeto - de duas abordagens mais usuais: de um lado, aquela da antropologia urbana (e suas variações); de outro, aquela da arte urbana (e suas variações)? Ficaríamos muito surpresos caso encontrássemos o grafite, prática discursiva que emerge na moderna cultura popular urbana, transubstanciado numa mídia stricto sensu? Embora assim acautelada, uma eventual investigação sobre os feitos e os fazeres atuais dos grafiteiros estaria irrevogavelmente fadada à marginalidade e às bordas do campo comunicacional?

Ainda que sejam várias, as questões até aqui listadas articulam-se e agrupam-se muito facilmente - em síntese, indicam sempre a necessidade de apreensão do objeto em sua tendência à ambiência midiática (sejam as redes, os canais ou os suportes midiáticos hegemônicos). Ao invés de afirmar 0 grafite como 
uma das mais expressivas formas da comunicação visual urbana, simplificando e encerrando aí 0 assunto (no que diz respeito às nossas expectativas comunicacionais, bem entendido), tratar-se-ia de apreender nele os caracteres refeitos, os traços alterados pela exposição, nos últimos 40 anos, a esse particular atrator que são os aparatos tecno-midiáticos que hoje povoam quase a totalidade da vida social.

Não há dúvidas de que a grafitagem de nosso tempo não é mais aquela encontrada nos muros de Paris a partir de maio de 1968 (assumido aqui como marco necessário para evitarmos maiores e desgastantes recuos históricos). Entretanto, no andamento incontido do tempo, o que tem agora resultado da incidência das lógicas, formatações e disposições midiáticas - afinal elas parecem sempre tão irresistíveis - sobre 0 grafite?

Tentaremos aqui dar maior curso a tais questões. Para tanto, para que possamos ensaiar respostas, iremos oportunizar: 1) a apresentação de parte de nosso material empírico (constituído de algumas peças midiáticas produzidas pelo coletivo de grafiteiros gaúchos UpGrade do Macaco); 2) as primeiras tentativas de exame desse material - à luz de categorias e molduras teóricas, vale salientar, que auxiliariam e garantiriam, por hipótese, a perseguição do foco comunicacionalmidiático que nos interessa.
Não se trata ainda de uma análise fina e aprofundada - a própria heterogeneidade do material selecionado impede, agora, um exercício deste tipo. Antes disso, a intenção é perspectivar firmemente nossos objetos a partir de considerações macro-teóricas que podem fornecer os horizontes epistêmicos das análises mais aproximadas que ficarão por vir.

0 justo enquadramento disciplinar adviria, estamos tentando acreditar, da capacidade de selecionar certos objetos limítrofes (mesmo entre objetos não prontamente aceitos como "midiáticos", como é o caso aqui do grafite) e fazer funcionar, sobre eles, categorias teóricoanalíticas que iluminem a trama tecno-midiática que os refaz, tornando-os justamente limítrofes, como dissemos (para evitar expressões mais desgastadas como "híbridos" ou "sincréticos"), afetando-os, senão em sua natureza, ao menos na graduação dos muitos traços que os definem e os fazem possuir relevância e sentido social.

\section{UpGrade do Macaco}

Há pouco mais de cinco anos, um pequeno grupo de jovens artistas vem fazendo inúmeras intervenções urbanas na cidade de Porto Alegre. Não se trata de um grupo formalmente organizado, mas fundado no trabalho cooperativo, inter-criativo, não-hierárquico e voluntário² ${ }^{2}$ №

A dissertação de mestrado defendida por Albuquerque (2006) tematiza o potencial e os produtos criativos de tais agrupamentos. Para auxiliar na compreensão dessas redes de sociabilidade, das dinâmicas interacionais e dos sentidos políticos que aí ganham terreno, conferir ainda os textos de Gonçalves (2007a, 2007b) e Cabral (2007). É útil consultar também os artigos de Brasil (2004), Beiguelman (2004) e Bastos (2004). 
princípio, dedicavam-se única e exclusivamente à prática do grafite, ao uso e à experimentação de algumas de suas técnicas mais conhecidas, tais como o stencil ${ }^{3}$ e os stickers ${ }^{4}$. Entretanto - e aí começa a insinuar-se a pertinência comunicacional que nos pareceu interessante acompanhar -, os integrantes do coletivo UpGrade do Macaco ${ }^{5}$ foram pouco a pouco incorporando lógicas e dispositivos midiáticos em seus trabalhos. Se no início as produções do grupo eram de caráter fundamentalmente artístico, expostas sempre no espaço público, inscritas nos muros e nas paredes disponíveis, junto aos postes de sinalização, nas regiões mais movimentadas da capital gaúcha, hoje se caracterizam também por um denso tratamento comunicacionalmidiático. É justamente a percepção desta singular "ambientação midiática" com a qual o grupo vem se afirmando na cena cultural da cidade que fez com que o tomássemos como foco prioritário de observações.

No caso, o estreitamento dos vínculos com 0 universo e as práticas das mídias vem se dando, por um lado, pela realização de trabalhos sob encomenda para agências de publicidade (como veremos em seguida); por outro lado, pelo emprego vigoroso de recursos e aparatos tecnológicos. Assim implementam-se tanto novos regimes de anunciabilidade pública (seja como estratégia espontânea de marketing, seja como impulso e disposição à midiatização), quanto lógicas de experimentação estética, onde a própria expansão do grafite, na busca de outras linguagens e na testagem de formas expressivas até certo ponto inéditas, também passa a ser tentada.

0 "upgrade" do grafite que aí ocorre caracterizase ainda pelo próprio redimensionamento das peças gráficas em suportes comunicacionais, como a fotografia e o site alimentado pelo grupo. Para 0 site (www.upgradedomacaco.com. br), além das fotos, deságuam também vários vídeos (ou melhor: quatro rápidas performances videográficas; na verdade, clipes promocionais de 15 segundos cada) que compõem um acervo de jogos expressivos e que funcionam como emblemas ou logotipos definidores de uma identidade audiovisual.

Além disso, o grupo mantém as versões on-line e impressa da revista Busca - a qual os vídeos digitais aludem -, e tem colaborado com outras publicações nacionais e internacionais, como

3 Os stencils são cartões contendo imagens, letras ou curtos dizeres vazados. Trata-se de pintar sobre eles, recolhendo-0s em seguida para novo uso. Na stencil art, esclarece Celso Gitahy (2002, p.39), "0 artista utiliza um cartão com formas recortadas que, ao receber o jato spray, só deixa vazar a tinta pelos orifícios determinados”.

Stickers são pequenos adesivos, feitos à mão ou fotocopiados em fitas plásticas, em papéis sofisticados ou não, que podem ser colados sobre qualquer superfície urbana.

0 grupo foi formado em junho de 2003 por Guilherme Pilla, Emerson Pingarilho, Geraldo Tavares, Bruno Novelli, Tinico Rosa, Carla Barth e Luiz Flávio Trabalho (a.k.a Trampo). Hoje, Wagner Pinto, Matheus Grimm e Stephan Doitschnoff também participam. 
a revista $R o j o$, editada em Barcelona. Aliás,

uma das últimas intervenções comunicacionais realizadas por integrantes do Coletivo foi justamente 0 trabalho feito para a UNISINOS, na campanha UNISINOS Arte nas Ruas ${ }^{6}$ (incluída aqui, entre as figuras abaixo $0^{7}$ ).
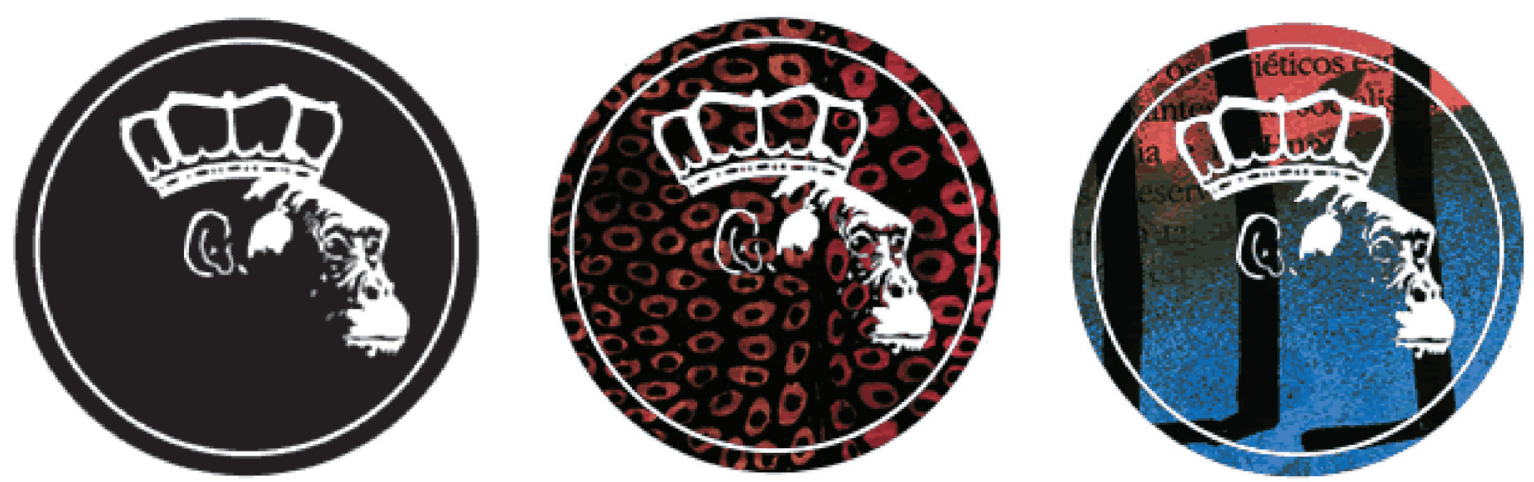

Figura 1: Diferentes versões do logotipo do coletivo UpGrade do Macaco

\section{IBUSC:A}

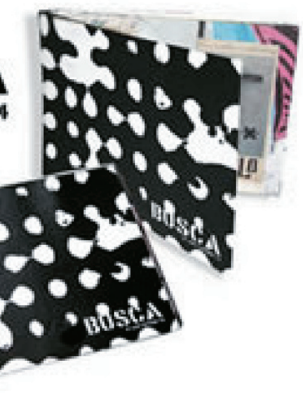

Figura 2: A primeira edição da Revista Busca, lançada em Porto Alegre, em outubro de 2004

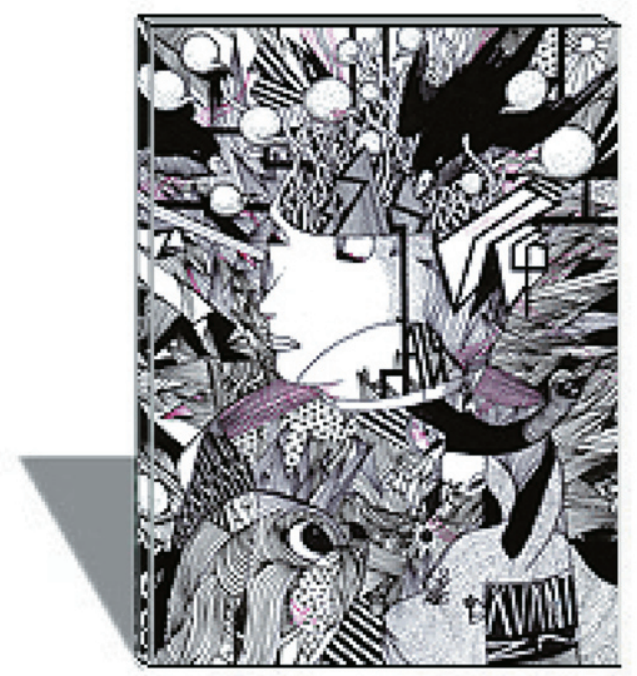

Figura 3: Revista Rojo, editada em Barcelona - Espanha, em 2006

6 A UNISINOS disponibilizou seu espaço de mídia externa para expor a obra de três dos componentes do grupo. Matheus Grimm, Bruno 9lli e Luis Flávio Trabalho, o Trampo, foram os escolhidos. Mais de 10 front-lights, nas dimensões de 3,6 x $7 \mathrm{~m}$, foram espalhados pela capital gaúcha. 0 projeto se estendeu até dezembro de 2006 e, a cada três meses, num sistema de rodízio, cada front-light recebeu uma intervenção em adesivo. No final do ano, a imagem inicial de cada peça havia sido modificada duas vezes. 


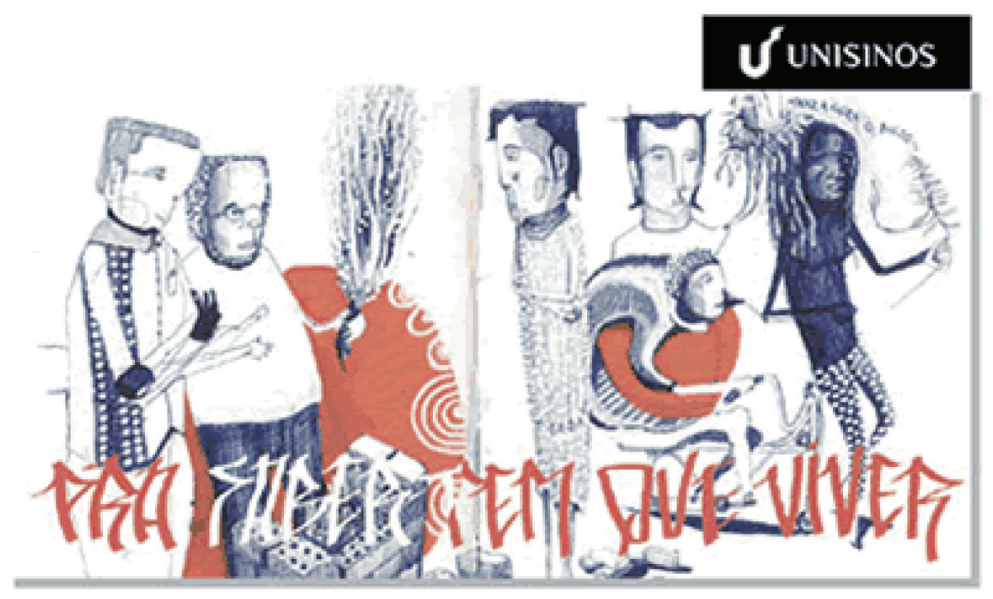

Figura 4: Peça de Matheus Grimm para a campanha UNISINOS Arte nas ruas

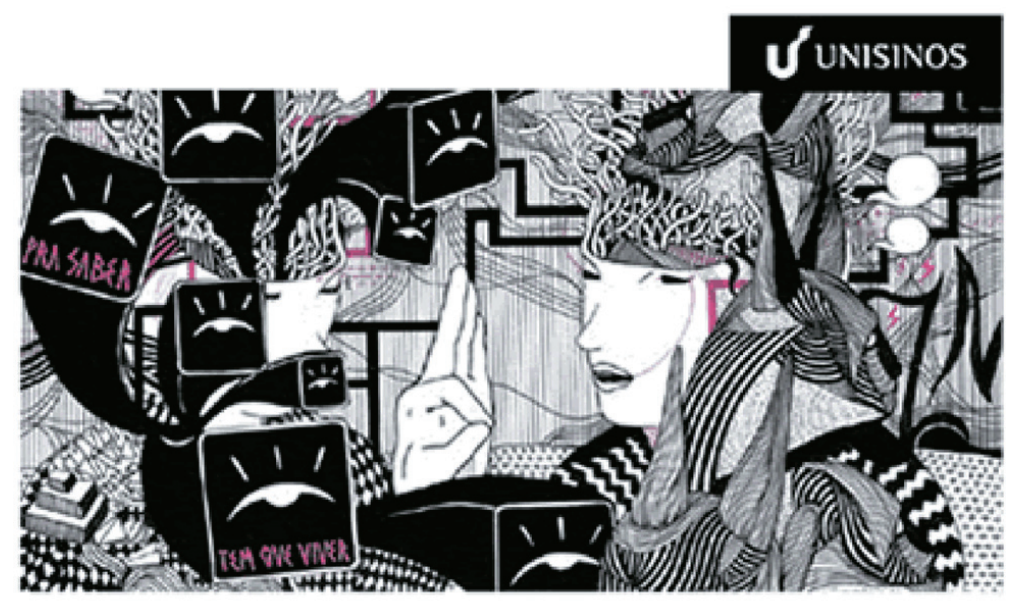

Figura 5: Peça de Bruno 9lli para a campanha UNISINOS Arte nas ruas

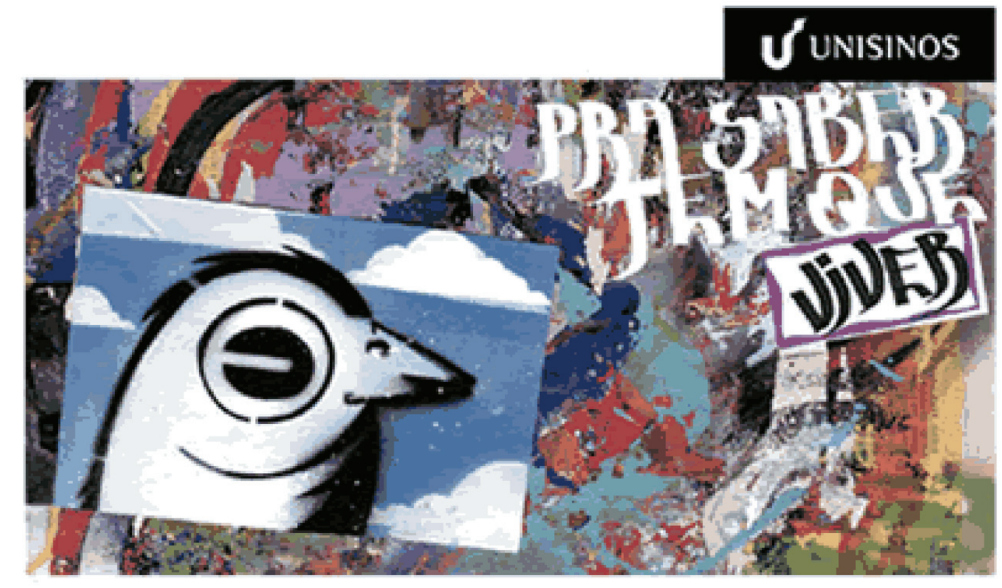

Figura 6: Peça de Luis Flávio Trampo para a campanha UNISINOS Arte nas ruas 
Merece ainda registro a própria

representatividade regional das criações do

UpGrade do Macaco. Nos últimos anos, as

produções do grupo vêm sendo comentadas

e abordadas por diversas mídias locais, tal

como acontece na coluna do escritor gaúcho

Paulo Scott, no Portal Terra Magazine ${ }^{8}$, ou

em matérias publicadas há pouco tempo nas

revistas Aplauso ${ }^{9}$ Type $^{10}$ e Wake Up ${ }^{11}$. E mesmo

revistas de circulação nacional, como Bravo $^{12} \mathrm{e}$

$R a i z^{13}$, também destacaram e repercutiram as

experiências desse Coletivo gaúcho.

Por fim, não se pode esquecer 0 amplo leque de

referências midiáticas que são exploradas tanto na

visibilização das peças quanto em sua elaboração

conceitual. Nos "manifestos" publicados no site

ou nas revistas impressas são freqüentes as

citações a autores de largo trânsito no campo

comunicacional, tais como François Lyotard, Guy

Debord e Gilles Lipovetsky, por exemplo.
Por tudo isso, o caso deixa entrever que uma

das expressões vitais das culturas urbanas

contemporâneas estaria sujeitando-se a processos

bem definidos de midiatização, remediação e de

flerte com formas midiáticas mais instituídas.

Poderíamos dizer, por exemplo, que a grafitagem

ali praticada deixa de ser apenas uma mídia

secundária para tornar-se também uma forma de

mídia terciária ${ }^{14}$. Aliás, é justamente enquanto

"mídia secundária" - embora a expressão

não seja tão usada - que o grafite é mais

freqüentemente tomado e discutido no campo

da Comunicação, desde os escritos de Armando

Silva (1987; 2001), Néstor Garcia Canclini (1998)

e Rossana Reguillo (2000). Mesmo estudos

mais recentes, como os de Pedro Russi (2002),

Débora Pennachin (2003), Cristina Pauli (2004)

e Rita Oliveira (2007), ao apostarem em outros

modos de amarra e ancoragem comunicacional,

estabilizam o grafite como mídia secundária.

Cf. http://terramagazine.terra.com.br. "Abordagem, eleição crítica e o UpGrade do Macaco" é o título da crônica de Paulo Scott. Entre outras coisas, o autor diz que "há consistência e versatilidade nas obras desses jovens - sua abordagem negocia abertamente, sem os receios e as certezas da dogmática acadêmica, sobre a escassez do lúdico, concatenando (sobretudo pela imagem) uma variedade de leituras afiadas (embora a coerência do conjunto ainda não seja perceptível) que transcendem a ditadura do óbvio e também o mero digital, ganhando as ruas, os grandes muros e os viadutos da cidade".

A matéria "Arte de rua invade Porto Alegre", foi publicada na revista Aplauso, n. 54, em março de 2004.

0 "A cidade e o graffiti. Concreto com cara de arte" é o título da matéria publicada na revista Type, n 04, em abril de 2004.

Matéria intitulada "Arte urbana. Massificada e gratuita”, publicada na revista Wake Up - Cultura, Informação e Consciência, $n^{\circ} 03$, publicada em setembro de 2005.

12 A matéria da revista Bravo - "0 eterno retorno do graffiti” - foi publicada na edição n.103, em março de 2006.

13 "Favor não pichar” é o título da reportagem de capa da revista Raiz - Cultura do Brasil, edição de abril de 2006.

As noções de mídia primária, secundária e terciária foram formuladas por Harry Pross, em Medienforschung (1972) (apud BAITELLO JÚNIOR, 2005). Basicamente, dizem respeito à necessidade de uso de quaisquer materiais, ferramentas ou instrumentos tecnológicos com o intuito de codificar informações, amplificando-as no tempo, no espaço ou no impacto que causam sobre 0 receptor. Respectivamente, o corpo, a escrita e a eletricidade seriam os exemplos mais emblemáticos de cada uma delas. 
Aqui, contudo, um tipo de remediação do grafite estaria acontecendo, determinantemente, pela incorporação dos (ou pela submissão aos) dispositivos tecno-midiáticos hoje amplamente disponíveis. "Remediação" deriva da expressão latina remederi e indica "curar, restaurar a saúde". Tal como apropriada por Jay David Bolter e Richard Grusin (1999), entretanto, o termo se refere às transformações ocorridas num produto midiático qualquer quando algumas de suas características (sua materialidade, sua expressividade, sua narratividade, suas estratégias habituais de representação e de usabilidade, etc) são imitadas, reproduzidas ou tomadas de empréstimo por outras mídias. Os autores distinguem dois tipos de remediação: imediação, caracterizada pela tendência ao apagamento da mediação tecnológica neste caso, a impressão é a de que se tem acesso direto à própria realidade mostrada, à mensagem transmitida ou à mídia predecessora -; e hipermediação, definida pela tendência à percepção consciente e contínua da própria interface midiática na qual se está atuando. Trata-se de uma distinção entre maior opacidade ou maior transparência do suporte tecnológico.

Estaria então a grafitagem, mais do que nunca como se uma nova etapa na evolução do grafite estivesse inaugurada -, fundindo-se às lógicas e aos dispositivos comunicacionais? As expressões de rua, mesmo em suas manifestações mais radicais e mais avessas à normatização - é bom lembrar que o grafite seria uma "mídia radical", conforme John Downing (2002) -, estariam sendo praticadas, contemporaneamente, em função da necessidade de submergir e/ou se diluírem neste espaço público virtual configurado pelos meios de comunicação de massa?

As peças aqui citadas, oscilando entre imediação (como é o caso dosfront-lights) e hipermediação (no caso dos vídeos), indicam, de qualquer forma, que 0 espaço midiático estaria revelando-se um desdobramento natural do espaço urbano. Haveria uma forte linha de continuidade, um claro continuum entre paisagens urbanas (landscapes) e paisagens midiáticas (mediascapes). 0 grafite nos colocaria, assim - segundo as palavras precisas de Fábio Duarte (2005, p.110) -, diante do desafio de assumir

[...] o espaço híbrido entre os universos físico e tecnológico como campo de reflexão - assumir que ambos são cada vez mais indissociáveis, infiltram-se uns nos outros, constituindo espacialidades múltiplas e mutáveis, e que só assim podemos pensar os desafios contemporâneos que os meios tecnológicos de comunicação e informação trazem ao espaço urbano.

Tais manifestações expressivas - no momento, não sabemos ao certo se podemos ainda chamálas de arte urbana, arte pública, comunicação visual urbana ou comunicação informal - estariam sendo então "traduzidas" e, como se não bastasse, estariam sendo cooptadas pelos valores e pelos interesses midiáticos mais convencionais. Não é à toa, por exemplo, que Guy Amado (documento eletrônico), comentando casos afins transcorridos em São Paulo, adota a expressão griffiti - 
"subversão com grife", diz ele. E continua: "Para além da superfície, no entanto, cabe aqui notar o peculiar processo de domesticação sofrido por uma linguagem essencialmente imbuída de um espírito transgressor - que se efetivaria quando 'proibida' ou minimamente não desejada -, agora travestida em plataforma institucional" (AMADO, [documento eletrônico]), servindo aos interesses administrativos de diversas corporações.

\section{Desenhar próteses tecnológicas}

Parte considerável da produção bibliográfica recente sobre 0 grafite possui, pelo menos, duas características marcantes. Primeiro, o caráter de mostruário visual de obras consideradas representativas - seja pela reputação do autor das peças mostradas, pela inventividade dos traços, pelo primor do acabamento obtido, pelo inusitado dos materiais aos quais se recorre, pela radicalidade do ponto urbano em que se inscrevem, etc. Todas essas edições, importa dizer, são invariavelmente caras e muito bem cuidadas. Segundo, é recorrente também um certo didatismo das técnicas empregadas - aqui aparece a indefectível oposição entre grafite e pichação, por exemplo, bem como toda sorte de glossários, "traduções", gírias e demais termos "nativos". Obviamente, tal finalidade é a de familiarizar o leitor ao que está sendo apresentado, envolvendo-o num oportuno e convidativo apelo plástico .

Menos perceptíveis, embora não menos presentes, são um certo ar de estética publicitária (nesse sentido, não deixa de ser um pouco paradoxal tamanho esmero e tamanha qualidade gráfica e editorial dos livros em causa!) e, principalmente, as menções a algo que estaria já para além das concepções mais usuais (tidas, na média, e conjuntamente, tanto pelo público leigo quanto pelos próprios grafiteiros) do que seja, afinal de contas, o grafite. Por um lado, tais referências apresentam a grafitagem como campo em expansão, prática em florescimento, que irá agregar e desenvolver novas técnicas, experimentar ainda novas linguagens e campos de aplicação. Por outro lado, apresentam-na como um tipo de produção cultural (contra-cultural, no mais das vezes) que já se encontraria batendo em seus limites, esgotando-se, vendo suas bases fundacionais, suas prerrogativas identitárias tornarem-se esgarçadas, desfiguradas demais. 0 grafite estaria defrontando-se então com alguns de seus confins, sejam eles dados pelas concessões ao mercado, pelo flerte com as artes, pela ocupação de outros espaços que não os espaços urbanos e pelo ingresso em novos circuitos dentre eles, obviamente, os circuitos midiático e cibermidiático. Este é o cenário contemporâneo. Nele se fala, por exemplo, em pós-grafite.

Não deixa de ser curioso, portanto, que livros tão dedicados e tão declaradamente engajados na causa da grafitagem, tão empenhados na defesa e na afirmação do universo "clássico" do grafite (como GANZ; MANCO, 2004; MANCO, 2005; BOU, 2005; PEREIRA, 2005; TORRES, 
2005; MEDEIROS, 2006; REINECKE, 2007, entre outros), falem reincidentemente em algo que chamam de pós-grafite.

De toda forma, embora não haja consenso quanto à caracterização exata disso que é também chamado de tech graff, a dificuldade que mais nos cabe tentar equacionar é a de definição do protagonismo das mediações tecnológicas nesse processo. Qual o impacto das mídias, com suas múltiplas caras e apelos, na instauração das "novas figurações do grafite"? Podemos ajuizar como essencialmente midiático o pós-grafite? Se fosse assim, o grafite, ao lado de outros objetos igualmente nobres, repousaria tranqüilo no coração mesmo da área da Comunicação.

Nossa suspeita, formulada aqui e em outros textos (SILVEIRA, 2007a; 2007b), é a de que os vínculos sanguíneos entre mídia e grafite são mais fortes do que parecem (ou do que nos habituamos a ver). Os tempos hipermidiáticos que correm se encarregam de deixar isso ainda mais claro. Num dos vídeos disponibilizados no site do UpGrade do Macaco, por exemplo, em meio aos mais corriqueiros ruídos urbanos - 0 som do vento soprando, falas desencontradas se sobrepondo, buzinas e sons de automóveis em disparada-, ouve-se uma frase certeira e muito insinuante: "desenhe suas próteses tecnológicas"!
Caso concebêssemos aqui o "comunicacionalmidiático" como algo fundamentalmente nucleado pela técnica, entender o desenho das próteses tecnológicas levadas hoje a cabo por diversos grupos de grafiteiros, dos gaúchos do UpGrade do Macaco aos novaiorquinos do Graffiti Research $L a b^{15}$, passando também pelo italiano TV Boy ${ }^{16}$ (e haveria ainda outros e outros exemplos), seria já uma empreitada justificada. Mais do que enxergar o grafite como forma de comunicação urbana, como mídia alternativa, mídia radical - ou do que mais se queira chamá-lo! -, importaria ver o grafite na mídia, sujeitandose aos processos de midiatização, deixando-se dizer, acomodando-se à necessidade de fazer-se visível (com os constrangimentos e as gramáticas restritivas que afloram nesses registros).

Entretanto, ao concebermos 0 "comunicacionalmidiático" como algo determinantemente (mas não exclusivamente) nucleado pela técnica, deveríamos reconhecer que o mais apropriado seria apreender a mídia no grafite, reinstituindo-o visceralmente. Então interessaria muito mais o modo como 0 grafite se refaz a partir dos aparelhamentos midiáticos, o modo como migra para 0 interior das mediações tecnológicas. Nesse caso, apreender a processualidade sociológica da midiatização seria pouco. Precisaríamos

Cf. www.graffitiresearchlab.com.

16 TV Boy é o pseudônimo de Salvatore Benintende, nascido em Palermo, em 1980. Envolvido com grafite e artes gráficas desde 1996, TV Boy vive e trabalha hoje em Barcelona. Cf. www.thetvboy.com. Importa reparar que talvez não seja gratuito 0 modo como estes artistas se nomeiam. 
considerar também as efetivas dinâmicas de remediação (aqui muito timidamente mapeadas), detalhando-as, esclarecendo-as em pormenor, refinando-as conceitualmente, traduzindo-as em procedimentos e categorias analíticas mais justas e refinadas. Será nosso próximo up grade.

\section{Referências Bibliográficas}

ALBUQUERQUE, Fernanda. Troca, soma de esforços, atitude crítica e proposição: uma reflexão sobre os coletivos de artistas no Brasil (1995-2005). Porto Alegre: UFRGS, 2006. Dissertação (Mestrado em Artes Visuais), Programa de Pós-Graduação em Artes Visuais, Universidade Federal do Rio Grande do Sul, Porto Alegre - RS, 2006, 130p.

ALZAMORA, Geane; BRASIL, André; FALCI, Carlos Henrique; JESUS, Eduardo de (orgs.). Cultura em fluxo: novas mediações em rede. Belo Horizonte: PUC - Minas, 2004.

AMAD0, Guy. Griffiti ou a transgressão domesticada. Disponível em: <www.descartavel.com/biblioteca/ grifitti.com>. Acesso em: 20 jun. 2006.

BAITELLO JÚNIOR, Norval. A era da iconofagia: ensaios de comunicação e cultura. São Paulo: Hacker, 2005.

BASTOS, Marcus. A cultura da reciclagem. In: ALZAMORA, Geane; BRASIL, André; FALCI, Carlos Henrique; JESUS, Eduardo de (orgs.). Cultura em fluxo: novas mediações em rede. Belo Horizonte: PUC - Minas, 2004, p.282-293.

BEIGUELMAN, Giselle. Admirável mundo cíbrido. In: ALZAMORA, Geane; BRASIL, André; FALCI, Carlos Henrique; JESUS, Eduardo de (orgs.). Cultura em fluxo: novas mediações em rede. Belo Horizonte: PUC - Minas, 2004, p.264-281.

BOLTER, Jay David; GRUSIN, Richard. Remediation: understanding new media. New York: MIT, 1999.
BOU, Louis. Street art: graffiti, stencils, stickers, logos. Barcelona: Instituto, 2005.

BRASIL, André. A arte do (des)controle. In: ALZAMORA, Geane; BRASIL, André; FALCI, Carlos Henrique; JESUS, Eduardo de (orgs.). Cultura em fluxo: novas mediações em rede. Belo Horizonte: PUC - Minas, 2004, p.232-245.

CABRAL, Ana Júlia. Espaço e poder: estratégias de resistência na sociedade de controle. In: CAIAFA, Janice; ELHAJJI, Mohammed (orgs.). Comunicação e sociabilidade: cenários contemporâneos. Rio de Janeiro: Mauad, 2007, p.75-89.

\section{CANCLINI, Néstor García. Culturas híbridas:} estratégias para entrar e sair da modernidade. São Paulo: EDUSP, 1998.

DOWNING, John. Mídia radical: rebeldia nas comunicações e nos movimentos sociais. São Paulo: SENAC, 2002.

DUARTE, Fábio. Espacialidades tecnológicas e vivências urbanas. Galáxia - Revista transdisciplinar de comunicação, semiótica e cultura (Programa de Pós-Graduação em Comunicação e Semiótica da PUC SP). São Paulo, n. 9, p.101-111, jun. 2005.

GANZ, Nicholas; MANC0, Tristan (orgs.). Graffiti: arte urbano de los cinco continentes. Barcelona: Gustavo Gili, 2004.

GITAHY, Celso. 0 que é graffiti? São Paulo: Brasiliense, 2002.

GONÇALVES, Fernando do Nascimento.

Comunicação, sociabilidade e ocupações poéticas da cidade. In: CAIAFA, Janice; ELHAJJI, Mohammed (orgs.). Comunicação e sociabilidade: cenários contemporâneos. Rio de Janeiro: Mauad, 2007a, p.55-74.

Resistência nômade: arte, colaboração e novas formas de ativismo na Rede. In: CONGRESSO BRASILEIRO DE CIÊNCIAS DA COMUNICAÇÃO 
(INTERCOM), 30., 2007b, Santos. Anais... Santos: INTERCOM, 2007b. CD-ROM.

MANCO, Tristan et al (org.). Graffiti Brasil. London: Thames \& Hudson, 2005.

MEDEIROS, Daniel (Boleta). Ttsss....: a grande arte da pichação em São Paulo, Brasil. São Paulo: Bispo, 2006.

OLIVEIRA, Rita de Cássia Alves. Estéticas

juvenis: intervenções nos corpos e na metrópole.

Comunicação, mídia e consumo, Escola Superior de Propaganda e Marketing (ESPM), São Paulo, ano 4, v. 4, n. 9, p. 63-86, mar. 2007.

PAULI, Cristina. Graffiti: Los jóvenes se adueñan de las diagonales. In: ENCONTRO DA ASSOCIAÇÃO LATINOAMERICANA DE INVESTIGAÇÃO EM COMUNICAÇÃO. 7., 2004. Anais... La Plata: Universidad Nacional de La Plata, 2004. CD-ROM

PENNACHIN, Débora. Signos subversivos: das significações de graffiti e pichação. Metrópoles contemporâneas como miríades sígnicas. In: CONGRESSO BRASILEIRO DE CIÊNCIAS DA COMUNICAÇÃO (INTERCOM), 26., 2003, Belo Horizonte. Anais... Belo Horizonte: INTERCOM, 2003. CD-ROM

PEREIRA, Sandrine. Graffiti. Paris: Fitway, 2005.

REGUILLO, Rossana. De máscaras, tribus y rituales: etnografia y otros textos nómades. In: REGUILLO, Rossana. Emergencia de culturas juveniles: estrategias del desencanto. Buenos Aires: Norma, 2000, p.97-139.

REINECKE, Julia. Post-Graffiti: between street, art and commerce. Corte Madera: Gingko, 2007.

RUSSI, Pedro. As pichações: paredes que falam.. In: BRAGA, Adriana; BORGES, Luis Fernando Rabello; AQUINO, Márcia Rodrigues (orgs.). Angulações e provocações na Cultura (Cadernos de Comunicação). São Leopoldo: UNISINOS, 2002, p.137-161.
SILVA, Armando. Punto de vista ciudadano:

focalización visual y puesta en escena del graffiti.

Bogotá: Caro y Cuervo, 1987.

Imaginários urbanos. São Paulo:

Perspectiva; Bogotá: Convênio Andrés Bello, 2001.

SILVEIRA, Fabrício. Grafite revisitado: estética e comunicação de rua em Porto Alegre. In: CAIAFA, Janice; ELHAJJI, Mohammed (orgs.). Comunicação e sociabilidade: cenários contemporâneos. Rio de Janeiro: Mauad, 2007a, p.35-54. Remediação e extensões tecnológicas do grafite. Galáxia - Revista transdisciplinar de comunicação, semiótica e cultura (Programa de Pós-Graduação em Comunicação e Semiótica da PUC SP). São Paulo, n. 14, p.95-109, dez. 2007b.

TORRES, Rosa Puig. Barcelona 1000 graffitis

(+ DVD travelling Barcelona graffitis). Barcelona: Gustavo Gili, 2005. 


\section{Upgrade do Macaco: expanded graffiti}

\section{Abstract}

Graffiti is not an unusual object in Communication studies. However, there is a certain naturalization of the debate on the subject. In the majority of the works that, since the 1980s, have been dedicated to the subject, graffiti is understood as a typical communicational form of the city environment. In other cases, less numerous, graffiti is generically equalized to some media forms (such as cartoons and music videos, for example). Anyway, in both perspectives, we don't have the perception that a communicational other, in a much more specific sense, is probably being engendered in the history of graffiti.

\section{Keywords}

Graffiti. Urban communication. Remediation.

\section{Upgrade do Macaco: grafiti expandido}

\section{Resumen}

Los grafitis no son un objeto inusual en los estudios de la Comunicación. Sin embargo, hay cierta naturalización de la discusión alrededor del tema. En la mayoría de los trabajos que, desde los años 1980, están dedicados al tema, los grafitis se afirman entendiendo sus aspectos comunicacionales diluidos en la cultura urbana. El grafiti sería así una forma de comunicación típica del ambiente de la ciudad. En otros casos, menos numerosos, el grafiti genéricamente se iguala rápidamente a formas mediáticas más instituidas (como los cartoons y los vídeos musicales, por ejemplo). De todas maneras, en una u otra perspectiva, no hay la percepción de que un "otro" comunicacional, en un sentido mucho más específico, puede estar engendrado en lo histórico del grafiti.

\section{Palabras clave}

Grafiti. Comunicación urbana. Remediación. 


\section{Expediente}

A revista E-Compós é a publicação científica em formato eletrônico da Associação Nacional dos Programas de Pós-Graduação em Comunicação (Compós). Lançada em 2004, tem como principal finalidade difundir a produção acadêmica de pesquisadores da área de Comunicação, inseridos em instituições do Brasil e do exterior.
E-COMPÓS I www.e-compos.org.br I E-ISSN 1808-2599

Revista da Associação Nacional dos Programas de Pós-Graduação em Comunicação. Brasília, v.11, n.1, jan./abr. 2008.

A identificação das edições, a partir de 2008, passa a ser volume anual com três números.

\section{CONSELHO EDITORIAL}

\section{Afonso Albuquerque}

Universidade Federal Fluminense, Brasil

Alberto Carlos Augusto Klein

Universidade Estadual de Londrina, Brasi

Alex Fernando Teixeira Primo

Universidade Federal do Rio Grande do Sul, Brasi

Alfredo Vizeu

Universidade Federal de Pernambuco, Brasil

Ana Carolina Damboriarena Escosteguy

Pontifícia Universidade Católica do Rio Grande do Sul, Brasil

Ana Silvia Lopes Davi Médola

Universidade Estadual Paulista, Brasil

André Luiz Martins Lemos

Universidade Federal da Bahia, Brasil

Ângela Freire Prysthon

Universidade Federal de Pernambuco, Brasil

Antônio Fausto Neto

Universidade do Vale do Rio dos Sinos, Brasil

Antonio Carlos Hohlfeldt

Pontifícia Universidade Católica do Rio Grande do Sul, Brasil

Arlindo Ribeiro Machado

Universidade de São Paulo, Brasil

César Geraldo Guimarães

Universidade Federal de Minas Gerais, Brasi

Cristiane Freitas Gutfreind

Pontifícia Universidade Católica do Rio Grande do Sul, Brasil

Denilson Lopes

Universidade Federal do Rio de Janeiro, Brasil

Eduardo Peñuela Cañizal

Universidade Paulista, Brasil

Erick Felinto de Oliveira

Universidade do Estado do Rio de Janeiro, Brasil

Francisco Menezes Martins

Universidade Tuiuti do Paraná, Brasil

Gelson Santana

Universidade Anhembi/Morumbi, Brasil

Hector Ospina

Universidad de Manizales, Colômbia

leda Tucherman

Universidade Federal do Rio de Janeiro, Brasil

Itania Maria Mota Gomes

Universidade Federal da Bahia, Brasil

Janice Caiafa

Universidade Federal do Rio de Janeiro, Brasil

Jeder Silveira Janotti Junior

Universidade Federal da Bahia, Brasil
John DH Downing

University of Texas at Austin, Estados Unidos

José Luiz Aidar Prado

Pontifícia Universidade Católica de São Paulo, Brasil

José Luiz Warren Jardim Gomes Braga

Universidade do Vale do Rio dos Sinos, Brasi

Juremir Machado da Silva

Pontifícia Universidade Católica do Rio Grande do Sul, Brasil

Lorraine Leu

University of Bristol, Grã-Bretanha

Luiz Claudio Martino

Universidade de Brasília, Brasil

Maria Immacolata Vassallo de Lopes

Universidade de São Paulo, Brasil

Maria Lucia Santaella

Pontifícia Universidade Católica de São Paulo, Brasil

Mauro Pereira Porto

Tulane University, Estados Unidos

Muniz Sodre de Araujo Cabral

Universidade Federal do Rio de Janeiro, Brasil

Nilda Aparecida Jacks

Universidade Federal do Rio Grande do Sul, Brasil

Paulo Roberto Gibaldi Vaz

Universidade Federal do Rio de Janeiro, Brasil

Renato Cordeiro Gomes

Pontifícia Universidade Católica do Rio de Janeiro, Brasil

Ronaldo George Helal

Universidade do Estado do Rio de Janeiro, Brasil

Rosana de Lima Soares

Universidade de São Paulo, Brasil

Rossana Reguillo

Instituto Tecnológico y de Estudios Superiores do Occidente, México

Rousiley Celi Moreira Maia

Universidade Federal de Minas Gerais, Brasil

Sebastião Carlos de Morais Squirra

Universidade Metodista de São Paulo, Brasil

Simone Maria Andrade Pereira de Sá

Universidade Federal Fluminense, Brasil

Suzete Venturelli

Universidade de Brasília, Brasil

Valério Cruz Brittos

Universidade do Vale do Rio dos Sinos, Brasil

Veneza Mayora Ronsini

Universidade Federal de Santa Maria, Brasil

Vera Regina Veiga França

Universidade Federal de Minas Gerais, Brasil

\section{COMISSÃO EDITORIAL}

Ana Gruszynski I Universidade Federal do Rio Grande do Sul, Brasil João Freire Filho I Universidade Federal do Rio de Janeiro, Brasil Rose Melo Rocha I Escola Superior de Propaganda e Marketing, Brasil

\section{CONSULTORES AD HOC}

Bianca Freire-Medeiros I Fundação Getulio Vargas, Brasil Josimey Costa da Silva I Universidade Federal do Rio Grande do Norte, Brasil Maria Conceição Golobovante I Pontifícia Universidade Católica de São Paulo, Brasil Marlyvan Moraes de Alencar I Centro Universitário SENAC-SP, Brasil Miriam de Souza Rossini I Universidade Federal do Rio Grande do Sul, Brasil Paulo Ribeiro I Pontifícia Universidade Católica do Rio de Janeiro, Brasil Rita Alves de Oliveira I Centro Universitário SENAC, Brasil

REVISÃO DE TEXTO E TRADUÇÃO I Everton Cardoso ASSISTÊNCIA EDITORIAL E EDITORAÇÃO ELETRÔNICA I Raquel Castedo
COMPóS I www.compos.org.br

Associação Nacional dos Programas de Pós-Graduação em Comunicação

Presidente

Erick Felinto de Oliveira

Universidade do Estado do Rio de Janeiro, Brasil erickfelinto@uol.com.br

Vice-presidente

Ana Silvia Lopes Davi Médola

Universidade Estadual Paulista, Brasil

asilvia@faac.unesp.br

Secretária-Geral

Denize Correa Araújo

Universidade Tuiuti do Paraná, Brasil

denizearaujo@hotmail.com 